\title{
So-Called Serous Carcinoma of the Uterine Cervix with BRCA2 Mutation: Case Report and Review of the Literature
}

\author{
Ruth Gabriela Herrera Gómez ${ }^{a}$ Delfyne Hastir ${ }^{b} \quad$ Aikaterini Liapi $^{a}$ \\ Ana Dolcan $^{a}$ Fernanda G. Herrera ${ }^{c}$ Patrice Mathevet ${ }^{d}$ \\ Apostolos Sarivalasis ${ }^{a}$ \\ aOncology Department, Lausanne University Hospital, University of Lausanne, Lausanne, \\ Switzerland; bPathology Department, Lausanne University Hospital, University of Lausanne, \\ Lausanne, Switzerland; 'Radiation Oncology Department, Lausanne University Hospital, \\ University of Lausanne, Lausanne, Switzerland; dDepartment of Obstetrics and Gynecology, \\ Lausanne University Hospital, University of Lausanne, Lausanne, Switzerland
}

\section{Keywords}

Rare tumors $\cdot$ Cervix serous carcinoma $\cdot B R C A$ mutation

\begin{abstract}
Serous carcinoma of the uterine cervix (SCUC) is now believed to be a morphological variant of an HPV-associated endocervical adenocarcinoma or a metastasis from a serous carcinoma of the upper tract. In terms of mutational status as detected by next-generation sequencing (NGS), this controversial entity has not been characterized yet. We describe the case of a patient with a carcinoma categorized as stage IVB SCUC, initially treated with carboplatin, paclitaxel, and bevacizumab, followed by maintenance with bevacizumab. After locoregional progression, radiotherapy was administered. Unfortunately, further progression was observed, and carboplatin was resumed. Considering the presence of a BRCA2 mutation as detected by NGS, treatment with a PARP inhibitor (olaparib) was decided and allowed disease control for 6 months. We believe that $B R C A$ mutation may be systematically searched in patients suffering from carcinomas formerly referred to as SCUC and that targeted treatments should be considered.
\end{abstract}




\section{Introduction}

Prior to the update of the WHO classification of female genital tumors in 2020 [1], serous carcinoma of the uterine cervix (SCUC) was suggested to be a very rare subtype of cervical carcinoma. SCUC has now been excluded from this classification, and it is suggested that the former entity represents a morphologic variant of HPV-associated endocervical adenocarcinoma or alternatively a metastasis or extension of a serous carcinoma of the upper tract including the fallopian tube, ovary, endometrium, or peritoneum.

First described in 1992 [2], the former entity SCUC was described to have a bimodal distribution with 2 peak ages at diagnosis: one before 40 years and the second after 54 years [2]. It is now known that the prognostic better type occurring in premenopausal patients relates to HPV-associated endocervical adenocarcinoma while HPV-independent cases were generally described in postmenopausal women often harboring an aberrant pattern of expression or a P53 mutation $[3,4]$.

Clinical as well as radiological features that may help distinguishing these 2 types of tumors are lacking as both forms may present with fluid vaginal discharge, abnormal vaginal bleeding, polypoid, exophytic, or ulcerated cervical mass, or hardened cervix [5]. Distant extra-pelvic metastases are often observed, especially in the para-aortic and cervical lymph nodes, lungs, peritoneum, ovary, liver, brain, and skin [5].

Considering the small number of cases described, the mutational profile of these tumors is poorly characterized. To the extent of our knowledge, this is the first report describing an advanced-stage FIGO IVB the so-called SCUC consisting of a probable metastasis or extension of an HPV-negative pure serous carcinoma with detection of a somatic BRCA2 mutation. We outline the treatment sequence including a first-line chemotherapy-bevacizumab combination, the second-line treatment at the progression, and the current maintenance olaparib treatment.

\section{Case Presentation}

A 68-year-old Caucasian woman, gravida (G) 1, para (P) 0, with menopause at 53 years, known for a conization 32 years earlier, and a low-grade HPV 33- and 68-positive squamous intraepithelial lesion (L-SIL) 2 years earlier, presented a pain in the lower right abdomen associated with vaginal bleeding (spotting) and abdominal bloating. Because of painful clinical examination, vaginal examination was not possible. An MRI of the pelvis showed a paracervical mass of $5 \mathrm{~cm}$ as well as peritoneal carcinomatosis and iliac adenopathy. Additionally, PET-CT showed a bone metastasis in the right iliac bone and vertebral body of L2 as well as infra-diaphragmatic lymphadenopathies.

Carcinogenic risk factors included a tobacco consumption of 25 pack years, weaned at 48 years. There was no family history of gynecological cancers. Laboratory investigations showed elevated CA125 of 4,695 kU/L (normal range $<35 \mathrm{kU} / \mathrm{L}$ ), and cervical smear was positive for HPV 33.

The patient underwent diagnostic laparoscopy and biopsies of the cervical lesion and the parametrial infiltration. Macroscopically, a peritoneal carcinomatosis was confirmed while ovaries and fallopian tubes appeared normal.

The surgical biopsies performed in the cervix and peritoneum showed a poorly differentiated carcinoma with a solid growth pattern composed of highly atypical cells with irregular nuclei, nucleoli, and numerous mitoses, with neither papillary nor mixed architecture. The carcinoma was mainly located in the cervical stroma close to residual endocervical glands with numerous lymphovascular invasions. The tumor expressed diffusely p16, WT1, ER, and

\section{Karger'}




\section{Case Reports in Oncology}

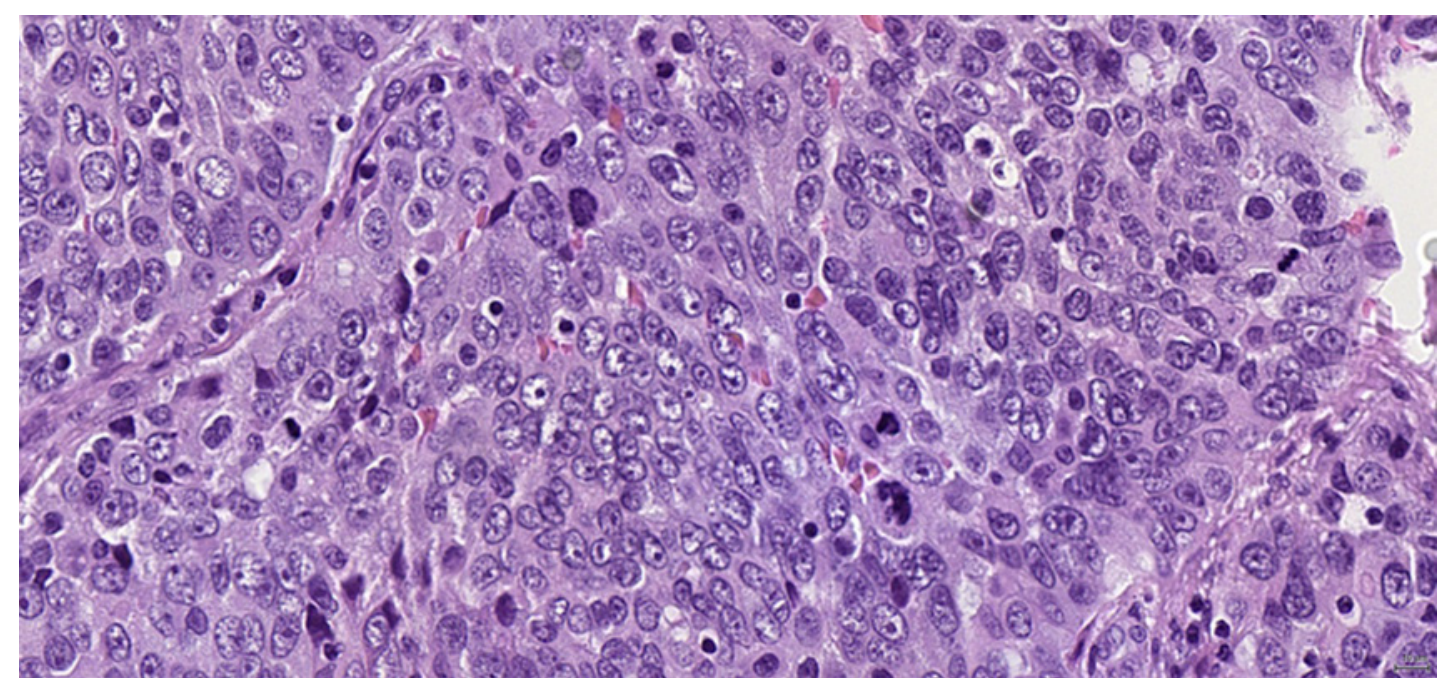

Fig. 1. High-grade serous carcinoma with very atypical epithelial cells with pleomorphic nuclei, nucleolus, moderately abundant eosinophilic cytoplasm, and numerous mitosis (H\&E. ×400).

PAX8 and focally PR and p53 mutational pattern of expression (null type). Vimentine was focally expressed, and CEA was negative. Because of high-risk HPV found in the PAP smear, HPV testing was performed on the DNA sample extracted from the FFPE block of the cervical biopsy showing negative results. The morphology and the immunophenotype was suggestive of a high-grade serous carcinoma (Fig. 1,2). Multidisciplinary tumor board discussion concluded in a primary cervical metastatic neoplasia stage IVB according to FIGO 2018, and the indication for a systemic chemotherapy was confirmed.

The patient benefited from 6 cycles of chemotherapy with carboplatin AUC5 and paclitaxel $175 \mathrm{mg} / \mathrm{m}^{2}$, with a second-look laparoscopy after the third cycle of treatment showing a good macroscopic response of the cervical mass and parametria, with the absence of peritoneal lesions at the abdominal level but persistence of macroscopic carcinosis at the pelvic level. Surgical cytoreduction was not performed. The patient completed the chemotherapy including bevacizumab $15 \mathrm{mg} / \mathrm{kg}$ from the fifth cycle, and subsequently, the patient continued with maintenance bevacizumab (Fig. 3).

During maintenance therapy with bevacizumab, the patient presented locoregional progression, and palliative external radiotherapy focused on the cervix was performed with a total of 39 Gy divided into 13 fractions. One month after the completion of radiotherapy, the patient developed iliac node involvement, and peritoneal progression was confirmed. Due to the histological diagnosis of pure serous HPV-independent carcinoma and the radiological localization of the tumor mass, the multidisciplinary tumor board decision was to treat the patient in a more personalized way as ovarian cancer instead of cervical cancer. Additional information was later provided by next-generation sequencing showing positivity for a somatic BRCA2 mutation (exon 11 [p. Val1238Glyfs * 21]).

We continued with carboplatin AUC4 in association with gemcitabine $800 \mathrm{mg} / \mathrm{m}^{2}$, but due to persistent grade 3 thrombocytopenia observed after 3 treatment cycles, chemotherapy was discontinued after having achieved a partial radiological response and a biological response. Thereafter, carboplatin AUC4 and liposomal doxorubicin were administered for a total of 6 chemotherapy cycles. Under this well-tolerated treatment, a good clinical and radiological response as well as a decrease of the tumor marker was observed.

Considering the presence of the BRCA2 mutation and the good response to platinum, we initiated olaparib, a PARP inhibitor, at $300 \mathrm{mg}$ twice daily, as maintenance treatment.

\section{Karger'}




\section{Case Reports in Oncology}

\begin{tabular}{l|l}
\hline Case Rep Oncol 2021;14:1792-1798 \\
\hline DOI: 10.1159/000520429 & $\begin{array}{l}\text { @ 2021 The Author(s). Published by S. Karger AG, Basel } \\
\text { www.karger.com/cro }\end{array}$ \\
\hline
\end{tabular}

Herrera Gómez et al.: So-Called Serous Carcinoma of the Cervix with BRCA Mutation
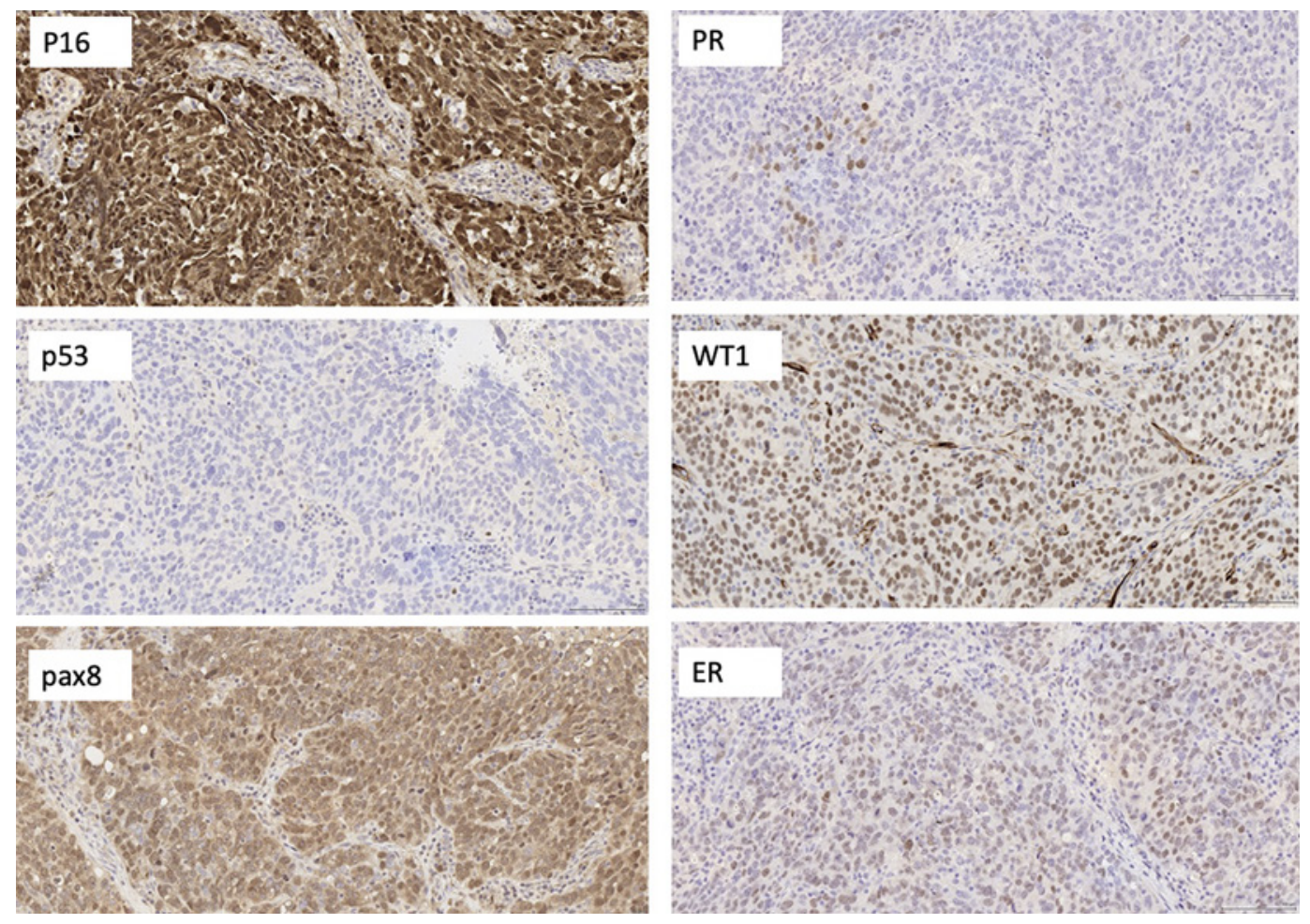

Fig. 2. Strong and diffuse positivity for $\mathrm{p} 16, \mathrm{PAX} 8$, and WT1, weak and diffuse positivity for estrogen receptor, and weak and focal positivity for progesterone receptor. Null-type mutational p53 immunostaining pattern $(\times 200)$.

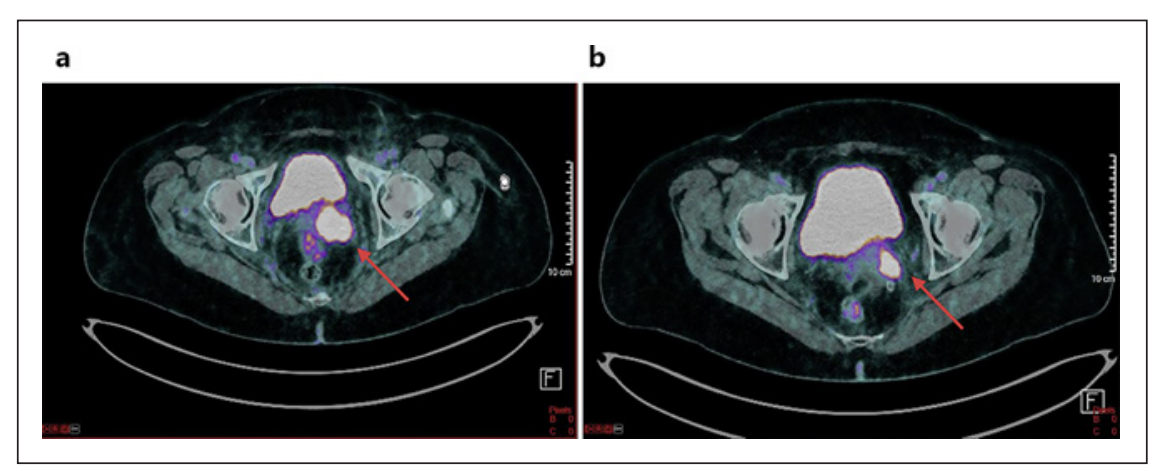

Fig. 3. Response to chemotherapy treatment as assessed by PET-CT before (a) and after (b) 3 cycles of chemotherapy showing regression of the paracervical mass.

This treatment was tolerated well, and as a treatment response, a radiological stable disease was documented for 6 months.

\section{Discussion}

According to the WHO classification of 2014, SCUC was characterized as a rare cervical cancer entity associated with a poor outcome $[2,6]$. Only 113 cases were reported in the literature with 68 cases characterized with immunohistopathological studies and 45 cases described in studies focused on treatment. Only 8 cases were treated with chemotherapy, 
Table 1. Summary of patient outcomes in patients with diagnosed SCUC treated with chemotherapy in the reported literature

\begin{tabular}{|c|c|c|c|c|}
\hline Author & Patients, $n$ & Clinical (FIGO, TNM) & Treatment & Outcome \\
\hline Kaplan et al. [7] & 1 & $\mathrm{pT} 1 / 1$ & $\begin{array}{l}\text { One cycle of neoadjuvance } \\
\text { with cisplatin + taxol followed } \\
\text { by concomitant radiation } \\
\text { therapy with cisplatin and } \\
3 \text { cycles of cisplatin + taxol }\end{array}$ & DFS 2 years \\
\hline Togami et al. [3] & $\begin{array}{l}1(1 / 12 \mathrm{au} \\
\text { total })\end{array}$ & pT1b1 N1 & $\begin{array}{l}\text { Surgery followed by } \\
\text { concomitant radiation } \\
\text { therapy with cisplatin } \\
\text { doxorubicin and } \\
\text { cyclophosphamide }\end{array}$ & DFS $2 \mathrm{~m}$ \\
\hline Tang et al. [8] & 1 & IIA (pT2a N1) & $\begin{array}{l}\text { Surgery followed by } \\
\text { concomitant radiation } \\
\text { therapy with paclitaxel } \\
\text { and carboplatin. In recurrence } \\
\text { neck LN-RT, and after cisplatin } \\
\text { followed by cisplatin and } \\
\text { gemcitabine }\end{array}$ & DFS $2 \mathrm{~m}$ \\
\hline Power et al. [12] & 1 & IVB (bone) & $\begin{array}{l}\text { Carboplatin with paclitaxel, } \\
6 \text { cycles }\end{array}$ & DFS $6 \mathrm{~m}$ \\
\hline Power et al. [12] & 1 & III & $\begin{array}{l}\text { Intermittent chemotherapy } \\
\text { with carboplatin alone and } \\
\text { in combination with paclitaxel } \\
\text { and hormonal therapy }\end{array}$ & DSF $28 \mathrm{~m}$, OS $36 \mathrm{~m}$ \\
\hline Yuksel et al. [9] & 1 & $\begin{array}{l}\text { IVB (liver, } \\
\text { peritoneum) }\end{array}$ & $\begin{array}{l}\text { Surgery followed by } \\
\text { carboplatin and paclitaxel }\end{array}$ & OS 18 months \\
\hline Khan et al. [10] & 1 & IVB (lung) & $\begin{array}{l}\text { Surgery followed by } \\
\text { carboplatin and paclitaxel }\end{array}$ & PFS unknown \\
\hline Ueda et al. [11] & 1 & IVB (lymph node) & $\begin{array}{l}\text { Carboplatin with paclitaxel } \\
\text { and surgery }\end{array}$ & Unknown \\
\hline
\end{tabular}

SCUC, serous carcinoma of the uterine cervix; DFS, disease-free survival; m, months; OS, overall survival.

either neoadjuvant or concomitant with radiotherapy, adjuvant, or systemic for metastatic disease (Table 1 [2, 3, 7-12]).

Neither the already mentioned revised WHO classification of 2020 nor the International Endocervical Adenocarcinoma Criteria and Classification (IECC) [13] published in 2018 consider SCUC as an independent diagnostic entity. HPV negativity and aberrant pattern of p53 expression/P53 mutation suggest that the patient may have suffered from a metastasis or a direct extension of a serous carcinoma originating from the fallopian tube, ovary, endometrium, or peritoneum. Regarding serous morphology, it has been shown that primary endocervical adenocarcinomas can mimic serous carcinoma in HPV-associated or less frequently in HPVindependent adenocarcinoma of the cervix [14].

The tumor was diffusely positive for PAX8, p16, ER, WT1, and an aberrant p53 expression (null type) supporting the tubo-ovarian/peritoneal origin [15]. While radiological presentation of the disease may be as well a defining feature of serous cervical carcinoma and generally allows a good initial evaluation, neither MRI nor PET-CT allowed to identify the primary in this case. 
Laparoscopic findings were both diagnostic and allowed evaluation for a possible surgical intervention. While the absence of ovarian involvement was shown, the peritoneal disease extent was important, and thus a complete peritoneal cytoreduction was not possible.

The BRCA2 mutation as detected in our case is observed in $15-25 \%$ of high-grade serous ovarian cancer but has not yet been described for the so-called SCUC. In the literature review, we identified a case suggestive of familial $B R C A$ mutation [7], but unfortunately $B R C A$ mutational status testing was not performed in this reported case. This may have impact on genetic counseling and treatment strategies.

Neither the European Society for Medical Oncology (ESMO), the National Comprehensive Cancer Network (NCCN), and the European Society for Radiotherapy and Oncology (ESTRO), nor the European Society for Gynecological Oncology (ESGO) propose specific therapeutic recommendations and apply the same algorithms for all patients with cervical cancer, preferring surgery in the early stages according to the classification of the International Federation of Gynecology and Obstetrics (FIGO).

In our case, considering the rarity of this disease, with a common characteristic of highgrade serous carcinoma such as ovarian origin and the presence of the BRCA mutation, we decided to personalize the treatment. In this case, the $B R C A$ mutational status may have prognostic value to forecast treatment response to chemotherapy treatment and allowed a tailored therapy. Induction therapy with platinum showed a remarkable response, which may be retrospectively explained by $B R C A$ mutational status as platinum sensibility is a common feature of $B R C A$-mutated tumors. Furthermore, the $B R C A$ mutational status justified an off-label use of olaparib in this case.

\section{Conclusion}

Our report illustrates features of a so-called HPV-independent SCUC with a BRCA2 mutation probably of tubo-ovarian or peritoneal origin. Even if serous-like patterns are described in the cervix, most of them are HPV-associated carcinoma and must be distinguished from pure serous carcinoma. With the advent of PARP inhibitors and their potential therapeutic implications on all $B R C A$-mutated tumors, systematic assessment of $B R C A$ mutational status should be recommended.

\section{Statement of Ethics}

The patient provided written informed consent for the publication of the clinical and laboratory data as well as radiological images. The study is exempt from ethics committee approval since it is a retrospective description of a clinical course of a patient treated with what we consider the best available treatment.

\section{Conflict of Interest Statement}

Ruth Gabriela Herrera Gómez declares no conflicts of interest. Delfyne Hastir declares no conflicts of interest. Aikaterini Liapi declares no conflicts of interest. Ana Dolcan declares no conflicts of interest. Fernanda G. Herrera declares no conflicts of interest. Patrice Mathevet declares no conflicts of interest. Apostolos Sarivalasis declares no conflicts of interest.

\section{Karger's}




\section{Case Reports in Oncology}

\begin{tabular}{l|l}
\hline Case Rep Oncol 2021;14:1792-1798 \\
\hline DOI: 10.1159/000520429 & $\begin{array}{l}\text { @ 2021 The Author(s). Published by S. Karger AG, Basel } \\
\text { www.karger.com/cro }\end{array}$ \\
\hline
\end{tabular}

Herrera Gómez et al.: So-Called Serous Carcinoma of the Cervix with BRCA Mutation

\section{Funding Sources}

The authors did not receive any funding.

\section{Author Contributions}

Ruth Gabriela Herrera Gómez contributed to investigation and writing (original draft); Delfyne Hastir contributed to investigation and writing (original draft); Aikaterini Liapi, Ana Dolcan, Fernanda G. Herrera, and Patrice Mathevet contributed to review and editing; Apostolos Sarivalasis contributed to investigation, writing (original draft), review and editing, and supervision.

\section{Data Availability Statement}

All data generated or analyzed during this study are included in this published article.

\section{References}

1 Cree IA, White VA, Indave BI, Lokuhetty D. Revising the WHO classification: female genital tract tumours. Histopathology. 2020;76(1):151-6.

2 Zhou C, Gilks CB, Hayes M, Clement PB. Papillary serous carcinoma of the uterine cervix: a clinicopathologic study of 17 cases. Am J Surg Pathol. 1998;22(1):113-20.

3 Togami S, Kasamatsu T, Sasajima Y, Onda T, Ishikawa M, Ikeda S, et al. Serous adenocarcinoma of the uterine cervix: a clinicopathological study of 12 cases and a review of the literature. Gynecol Obstet Invest. 2012; 73(1):26-31.

4 Zhou C, Matisic JP, Clement PB, Hayes MM. Cytologic features of papillary serous adenocarcinoma of the uterine cervix. Cancer. 1997;81(2):98-104.

5 Jonska-Gmyrek J, Zolciak-Siwinska A, Gmyrek L, Michalski W, Poniatowska G, Fuksiewicz M, et al. Serous carcinoma of the uterine cervix, an extremely rare aggressive entity: a literature review. Gynecol Obstet Invest. 2018;83(3):220-6.

6 Gilks CB, Clement PB. Papillary serous adenocarcinoma of the uterine cervix: a report of three cases. Mod Pathol. 1992;5(4):426-31.

7 Kaplan EJ, Caputo TA, Shen PU, Sassoon RI, Soslow RA. Familial papillary serous carcinoma of the cervix, peritoneum, and ovary: a report of the first case. Gynecol Oncol. 1998;70(2):289-94.

8 Tang W, Zhang Z, Yao H, Zeng Z, Wan G. Papillary serous carcinoma of the cervix mixed with squamous cells: a report of the first case. Gynecol Oncol Case Rep. 2013;6:22-4.

9 Yuksel H, Sezer SD, Kucuk M, Riza Obadasi A, Doger FK. Papillary serous adenocarcinoma of the uterine cervix: a case report. Eur J Gynaecol Oncol. 2011;32(2):240-2.

10 Khan M, Gilman AD, Nizami S, Barbaryan A, Ali AM, Mirrakhimov AE. Papillary serous carcinoma of the uterine cervix with lung metastasis. Case Rep Oncol Med. 2014;2014:683103.

11 Ueda M, Koshiyama M, Yamaguchi A, Ukita S, Ukita M, Hishikawa K, et al. Advanced papillary serous carcinoma of the uterine cervix: a case with a remarkable response to paclitaxel and carboplatin combination chemotherapy. Rare Tumors. 2012;4(1):e1.

12 Power DG, McVey GP, Delaney DW, Rea D, D'arcy T, Daly PA, et al. Papillary serous carcinomas of the uterine cervix and paraneoplastic cerebellar degeneration: a report of two cases. Acta Oncol. 2008;47(8):1590-3.

13 Stolnicu S, Barsan I, Hoang L, Patel P, Terinte C, Pesci A, et al. International endocervical adenocarcinoma criteria and classification (IECC): a new pathogenetic classification for invasive adenocarcinomas of the endocervix. Am J Surg Pathol. 2018;42(2):214-26.

14 Wong RW, Ng JHY, Han KC, Leung YP, Shek CM, Cheung KN, et al. Cervical carcinomas with serous-like papillary and micropapillary components: illustrating the heterogeneity of primary cervical carcinomas. Mod Pathol. 2021;34(1):207-21.

15 Nofech-Mozes S, Rasty G, Ismiil N, Covens A, Khalifa MA. Immunohistochemical characterization of endocervical papillary serous carcinoma. Int J Gynecol Cancer. 2006;16 Suppl 1:286-92. 